\title{
Catching-up effects in the logistics industry and the dynamic linkages with international trade and economic growth: Empirical evidence from an international panel dataset
}

\author{
Ioannis Katrakylidis ${ }^{1} \bullet$ Michael Madas $^{2, *}$ \\ ${ }^{1}$ Aristotle University of Thessaloniki, Thessaloniki, Greece \\ ${ }^{2}$ University of Macedonia, Thessaloniki, Greece
}

Received: 13 January 2020

Revised: 30 March 2020

Accepted: 30 March 2020

\begin{abstract}
We analyze the dynamic linkages among Logistics, Trade and Economic Growth for a panel of 39 countries over the period 2007-2018. In particular, we investigate whether these countries exhibit the tendency to catch up, in terms of logistics performance, with the leader country, using methodologies of "convergence analysis" appropriate for the notions of stochastic convergence and $\beta$-convergence and perform Granger-causality tests among a catching up variable (the LPI of each country relative to the LPI of Germany), trade openness and economic growth. The findings reveal rather weak evidence of catching-up effects with Germany. As far as causality is concerned, trade and economic growth further enhance the global tendency in logistics performance to catch-up with the dominant Germany while convergence in logistics is found to directly support economic growth but not trade.
\end{abstract}

Keywords: logistics; stochastic convergence; catching-up; panel unit-root tests; Granger causality

JEL Classification Codes: C23, C33, C54, L91 O47

\section{Introduction}

The development of the logistics and transport sector has an indisputably positive contribution on economic growth by facilitating production, consumption and trade (Gani, 2017). Costs of production as well as expenses for importing and exporting activities can be substantially reduced by investments in transport infrastructure. At the same time, logistics and transport advancements enable trade development and strengthen country's trade performance and competitiveness (Dee and Findlay, 2006; Hoekman and Nicita, 2011). This can be viewed under the

\footnotetext{
*Corresponding author. E-mail: katrakyl.john@gmail.com.

Citation: Katrakylidis, I., and Madas, M. (2020) Catching-up effects in the logistics industry and the dynamic linkages with international trade and economic growth: Empirical evidence from an international panel dataset, Economics and Business Letters, 9(3), 197-205.
}

DOI: 10.17811/ebl.9.3.2020.197-205 
prism of any improvements, quality upgrades or expansion of physical transportation infrastructure, import/export efficiency, competitive pricing of shipments or any other logistics-driven factor affecting the cost of doing business (Arvis et al., 2012; Hausman et al., 2013; PortugalPerez and Wilson, 2012).

The grid of relationships becomes further complicated when bi-directional linkages among these macroeconomic variables are brought forward. The development of international trade triggers demand for logistics services with the latter serving as the "vehicle" of international trade. As a result, new investment opportunities and business growth prospects emerge in the macroeconomic landscape (Lee and Rodrigue, 2006; Vasiliauskas and Barysiene, 2008). Empirical evidence has largely unfolded causal relationships between logistics, international trade and economic growth. Small Asian countries (e.g., Singapore, Hong Kong) have experienced high economic growth mainly due to their large investments in logistics which have drastically enhanced international trade. On the other hand, China, one of the largest economies in the world, demonstrated high growth rates mostly driven by exports' growth. This became largely possible due to the development of advanced logistics networks accommodating raw materials and final product flows to developed economies of the world.

Despite the empirical evidence about this complex grid of causal relationships, existing literature has mostly focused on the investigation of dynamic linkages and causal effects in bivariate relationships (Katrakylidis and Madas, 2019). Relevant research can be organized in two main research streams. The first stream of research deals with the analysis of the relationship - and in some cases the direction of causal effects - between logistics/transport infrastructure and economic growth (Rietveld, 1989; Berndt and Hansson, 1992; Kessides, 1996; Kumar Sharma and Singh Kushwaha, 2017) or competitiveness indicators (Ekici et al., 2016). The second stream pertains to the analysis of dynamic relationships between the logistics and transport sector and international trade. It is worth noting here that both directions of causation have been detected in existing literature. Most researchers placed the emphasis on the exploration of effects of logistics on trade facilitation and openness and argued that improvements in logistics constitute key determinants of trade facilitation and growth (Wilson et al., 2003; Arvis et al., 2007; 2010; Hoekman and Nicita, 2011; Hausman et al., 2013; Gani, 2017; Kabak et al., 2018; Çelebi, 2019). Other researchers studied causal effects of international trade on the logistics and transport sector. Under this line of research, the impact of trade facilitation measures on the development and growth of containerized trade and its associated logistics services represented the focal point of analysis (Lee and Rodrigue, 2006; Vasiliauskas and Barysiene, 2008; Nguyen and Tongzon, 2010).

Multivariate relationships involving causal effects from/to logistics and transport have not been sufficiently addressed in existing literature. Katrakylidis and Madas (2019) studied the relationships between countries' logistics performance, international trade and economic growth and identified causal linkages among them (both in the long and the short run) based on a sample of 39 countries worldwide over the period 2007-2018. The score of the World Bank's Logistics Performance Index (LPI) has been used to express the logistics performance of the respective countries. LPI provides a weighted measure of the logistics performance of 160 countries in terms of various performance dimensions of "friendliness" of trade logistics and varies substantially with countries. According to LPI 2018 rankings, a large logistics performance gap is observed between top performer (e.g., Germany, Sweden, Belgium) and low performer countries (e.g., Afghanistan, Angola, Burundi, Niger, Sierra Leone) (Arvis et al., 2014). In this paper, we provide an extension of the trivariate causality analysis conducted by Katrakylidis and Madas (2019) with the ultimate objective to evaluate the improvements in the logistics sector performance globally by means of convergence analysis (Holmes et al., 2014; Tsanana and Katrakilidis, 2014; Fallahi, 2017). In particular, we explore possible catching-up effects between the various countries and Germany exhibiting the highest LPI score. Moreover, and 
since, to the best of our knowledge, there is no research effort that causally relates global convergence in the logistics sector with economic development accounting for the impacts of the international trade growth, we further aim at exploring possible causal links running from trade and GDP growth to LPI convergence.

The remainder of this paper is structured into three sections. Section 2 presents the methodological aspects of our empirical analysis. Section 3 presents the underlying data, Section 4 discusses the associated empirical results and Section 5 summarizes the key conclusions of the paper.

\section{Methodological issues}

\subsection{The convergence hypothesis}

In the relative literature of convergence, researchers provide various definitions of the income convergence hypothesis. Sala-i-Martin (1996) provides probably the most-widely known definition of $\beta$ convergence contemplating that "there is absolute $\beta$ convergence if poor economies tend to grow faster than rich ones". The first research efforts on convergence were cross-sectional studies with $\beta$ convergence to hold if the coefficient of a regression of GDP per capita growth rates on initial levels was negative.

The more recent time series approaches on convergence focus on the notion of "stochastic" convergence (shocks to relative incomes should be temporary), that is, per capita income disparities between economies should follow a stationary process.

The hypothesis that relative incomes are converging stochastically can be examined by testing for a unit root in the logarithm of the ratio of per capita income in country $i$ relative to the group average or to the leader. Rejection of the unit root null hypothesis is then considered an evidence of convergence. Stochastic convergence can be evaluated by the use of several versions of unit root tests for time series such as the conventional Dickey-Fuller (ADF) unit root tests, the DFGLS, the Philips-Perron, and the KPSS stationarity test. Analogues tests are applied for panel data samples.

If no regressors are included in the procedure for testing the unit root hypothesis, stochastic convergence is consistent with the notion of "absolute" or "unconditional" convergence. In contrast, if a constant term is included in each test, stochastic convergence is consistent with conditional convergence and country-specific compensating differentials.

\subsection{A test of $\beta$-convergence}

Carlino and Mills (1993) estimate the intercept and trend coefficients for the relative income series in countries for which there is evidence of stochastic convergence. Opposite signs of the intercept and slope coefficients indicate that countries, whose relative per capita income is initially below the group average, are trending (converging) up towards the average and vice versa. Tomljanovich and Vogelsang (2002) use the following regression for relative income:

$$
R I_{i t}=\mu+\beta t+u_{i t}
$$

where, $R I_{i t}$ is the log of relative per capita GDP (LLPI in this study) in country $i$ at time $t$, that is regressed on a constant and a linear time trend, and $u_{i t}$ follows a stationary process, $\beta$ represents the average growth of $R I_{i t}$ over time and $\mu$ represents the initial level of $R I_{i t}{ }^{e}$.

\section{Data}

In the context of this empirical analysis, our study employs annual data from 39 countries (reported in the Appendix) over the period 2007-2018. More particularly, the collected time series data sourced from the World Development Indicators Statistical Database of the World Bank and concerns the Logistics Performance Index, the Openness to Trade and the Gross Domestic Product per Capita. 
The World Bank measures countries' trade logistics performance since 2007 by usage of an index known as the Logistics Performance Index (LPI). The index ranges from 1 to 5, with a higher score representing better performance and is calculated by analyzing six main components: customs, infrastructure, international shipments, logistics quality and competence, tracking and tracing, and timeliness.

Regarding the Trade Openness variable, it is expressed in terms of the sum of exports and imports of goods and services measured as a share of Gross Domestic Product (GDP). Finally, Gross Domestic Product (GDP) per capita represents the gross domestic product divided by midyear population. More specifically, we use GDP per capita where gross domestic product has been converted to international dollars using purchasing power parity rates (PPP). Data are in constant 2011 international dollars.

\section{Empirical results}

In the first step, it is essential to determine the integration properties of the involved series in to avoid the so-called problem of spurious regression. In this direction, we apply complementary five panel unit-root tests, the Levin, Lin \& Chu test (LLC) (Levin et al., 2002) and the Breitung test (BR) (Breitung, 2000), both assuming a common root process and the Im, Pesaran and Shin test (IPS) (Im et al., 2003), the Fisher-ADF test (FADF) (Maddala and Wu, 1999) and the Fisher-PP test (FPP) (Choi, 2001) assuming individual root process. The results are shown in Tables 1 and 2 below.

The findings reported in Table 1 support that LLPI in 2 out of 5 tests do not reject the null hypothesis of a unit root (non-stationarity), while TRP and LY reject the null in 4 and 5 out of 5 tests, respectively. In brief, based on the above, in terms of majority, we may consider that LLPI is a non-stationary series, while TRP and LY are stationary. When testing the series in first difference form, they all clearly turn to stationary. Then, we continue by accounting only for individual effects. The results are reported in Table 2 below.

Table 1. Panel Unit-root tests (with constant and trend).

\begin{tabular}{l|ccc|ccc}
\hline \hline & \multicolumn{3}{|c|}{ Levels } & \multicolumn{3}{c}{ First Differences } \\
& Individual effects, individual linear trends & \multicolumn{3}{c}{ Individual effects, individual linear trends } \\
& LLPI & TRP & LY & LLPI & TRP & LY \\
\hline \multirow{2}{*}{ LL C } & -7.82334 & -17.8525 & -9.82874 & -13.1138 & -35.4951 & -19.1032 \\
& $(0.0000)$ & $(0.0000)$ & $(0.0000)$ & $(0.0000)$ & $(0.0000)$ & $(0.0000)$ \\
BR & 1.91253 & -5.66491 & 1.93614 & -3.47944 & -7.19919 & -0.11952 \\
& $(0.9721)$ & $(0.0000)$ & $(0.9736)$ & $(0.0003)$ & $(0.0000)$ & $(0.4524)$ \\
IPS & -3.60216 & -8.13019 & -2.53566 & -3.21373 & -11.9849 & -6.03289 \\
& $(0.0002)$ & $(0.0000)$ & $(0.0056)$ & $(0.0007)$ & $(0.0000)$ & $(0.0000)$ \\
& 134.670 & 196.313 & 115.649 & 150.479 & 333.492 & 200.810 \\
FADF & $(0.0001)$ & $(0.0000)$ & $(0.0036)$ & $(0.0000)$ & $(0.0000)$ & $(0.0000)$ \\
& 57.9752 & 181.907 & 113.555 & 29.3220 & 303.363 & 254.683 \\
& $(0.9565)$ & $(0.0000)$ & $(0.0053)$ & $(1.0000)$ & $(0.0000)$ & $(0.0000)$ \\
\hline \hline
\end{tabular}

Note: Panel unit-root test include intercept and time trend; the optimal number of time lags is chosen by SBC up to a maximum of two lags. Numbers in parentheses are p-values. 
Table 2. Panel Unit-root tests (Only constant).

\begin{tabular}{l|ccc|ccc}
\hline \hline & \multicolumn{3}{|c|}{$\begin{array}{c}\text { Levels } \\
\text { Individual effects }\end{array}$} & \multicolumn{3}{c}{ First Differences } \\
& Individual effects & LY \\
\hline \multirow{2}{*}{ LLC } & LLPI & TRP & LY & LLPI & TRP & LY \\
& -8.15 & -6.594 & -5.66 & -9.68 & -30.09 & -18.30 \\
BR & $(0.00)$ & $(0.00)$ & $(0.00)$ & $(0.00)$ & $(0.00)$ & $(0.00)$ \\
& - & - & - & - & - & - \\
IPS & $(-)$ & $(-)$ & $(-)$ & $(-)$ & $(-)$ & $(-)$ \\
& -5.60 & -2.01 & 1.01 & -5.81 & -18.29 & -11.16 \\
& $(0.00)$ & $(0.02)$ & $(0.84)$ & $(0.00)$ & $(0.00)$ & $(0.00)$ \\
FISHER ADF & 159.03 & 98.87 & 69.69 & 166.99 & 398.48 & 258.84 \\
& $(0.00)$ & $(0.05)$ & $(0.73)$ & $(0.00)$ & $(0.00)$ & $(0.00)$ \\
& 119.949 & 104.002 & 74.5835 & 72.3481 & 385.977 & 231.418 \\
& $(0.0016)$ & $(0.0262)$ & $(0.5886)$ & $(0.6592)$ & $(0.0000)$ & $(0.0000)$ \\
\hline \hline
\end{tabular}

Note: Panel unit-root test include only intercept: the optimal number of time lags is chosen by SBC up to a maximum of two lags. Numbers in parentheses are p-values.

The results provide evidence against the presence of a unit root (rejection of the null hypothesis) for LLPI and TRP in 5 out of 5 statistics in level form and almost similar indications in first differences. However, LY is found non-stationary (acceptance of the null hypothesis of a unit root) in level form, in 3 out of 5 statistics but stationary in first difference form. Therefore, we may accept that the order of integration of the examined variables could be characterized slightly inconclusive for LLPI and LY, while TRP is clearly stationary, I(0).

Based on the brief description given previously in the methodological presentation of convergence, we construct the following variable:

$$
L P I C O N V=\log \left(L P I_{i, t}-L P I_{\text {Germany }, t}\right)
$$

The adopted strategy to test the issue of convergence (catching up) in Logistics Performance for the studied group of countries is straightforward. First, we apply panel unit-root tests on LPICONV with no fixed individual effects in order to check whether an absolute convergence process is present. Second, if the null of unit root cannot be rejected, the same panel unit root tests but with fixed individual effects are implemented in order to identify possible conditional convergence dynamics. Finally, if the unit root hypothesis always holds, then we consider that the group is characterized by stochastic divergence.

Table 1. Panel unit root test results for convergence.

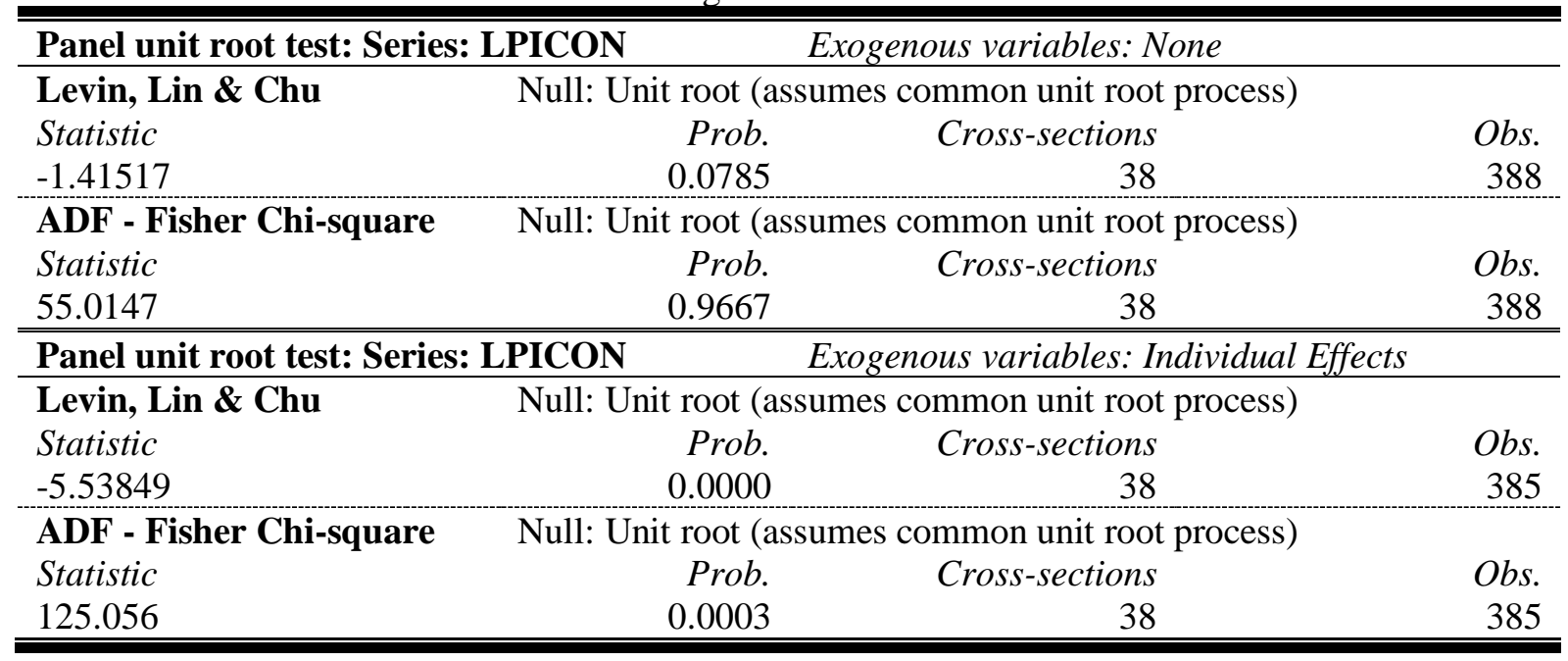


Table 2. $\beta$-Convergence test.

\begin{tabular}{lcccr}
\hline \hline Panel Least Squares & & \multicolumn{3}{c}{ Depend. Var. LPICON } \\
Variable & Coefficient & Std. Error & t-Statistic & Prob. \\
\hline C & -0.678326 & 0.040812 & -16.62070 & 0.0000 \\
@TREND & 0.000743 & 0.006285 & 0.118164 & 0.9060 \\
\hline \hline
\end{tabular}

We apply the LLC test proposed by Levin et al. (2002) and the Fisher-ADF test proposed by Maddala et al. (1999) and Choi (2001) which are homogeneous and heterogeneous panel unitroot tests, respectively, based on the assumption of independent cross-section units. In LLC, the alternative hypothesis is that no series contains a unit root (all are stationary), while in Fisher-ADF the alternative allows unit roots for some (but not all) of the series.

We apply the tests with no individual effects and with individual effects. The results are presented in Table 3 below.

Based on the above reported results, when no individual effects are included, the null of unit root cannot be rejected by all tests, hence revealing non-stationarity and consequently absence of absolute convergence. However, according to the results presented in the lower panel of the above table, the evidence supports the existence of conditional convergence (catching up), since all tests now clearly reject the null hypothesis of unit root in favor of stationarity.

In addition, we apply a test of $\beta$-convergence (Table 4) proposed by Carlino and Mills (1993) (please refer to Section 2). Carlino and Mills (1993) argued that, if the examined countries are converging or catching up, then regression of the log relative examined variable (LPICON in our study) on an intercept and trend should yield statistically significant and of opposite sign coefficients.

The above results confirm the catching up effect of the examined group of countries with Germany, given that the constant term and the trend coefficient are of opposite sign. However, the lack of statistical significance in one of the two coefficients supports evidence of a rather weak movement towards convergence.

In a final stage, and having established stationarity for the relative LLPI and evidence of catching up with the benchmark country, we proceed with the examination of possible causal effects between the LLPI convergence variable, trade openness and GDP. We estimate a trivariate VAR system for LPICON, TRP and LY, where the optimal lag length is found to be equal to 3 by means of Akaike Information Criterion and we apply Granger causality tests (Granger, 1969), using the F statistic (Table 5).

The above findings reveal that TRP and LY affect causally LPICON (p-values 0.0237 and 0.0003, respectively). In particular, there are feedback effects (two-way causality) between LY and TRP (p-value 0.0002), while LPICON causally affects LY (p-value 0.0006) but not TRP (p-value 0.2465 ).

Table 3. Pairwise Granger Causality Tests.

\begin{tabular}{lrrr}
\hline \hline Sample: 2007 2018 (Lags: 3) & & & \\
\hline Null Hypothesis & Obs. & F-Statistic & Prob. \\
TRP does not Granger Cause LPICON & 342 & 3.19402 & 0.0237 \\
LPICON does not Granger Cause TRP & & 1.38730 & 0.2465 \\
LY does not Granger Cause LPICON & 342 & 6.32976 & 0.0003 \\
LPICON does not Granger Cause LY & & 5.91915 & 0.0006 \\
LY does not Granger Cause TRP & 342 & 6.89637 & 0.0002 \\
TRP does not Granger Cause LY & & 3.82544 & 0.0102 \\
\hline \hline
\end{tabular}




\section{Summary and conclusions}

In this paper, we analyzed the dynamic linkages among Convergence in the Logistics Performance Index, Trade Openness and Economic Growth for a sample of 39 countries over the period 2007-2018. In particular, we first examined whether the countries of our sample present the tendency to catch up with the leader country, in terms of logistics performance, using methodologies of "convergence analysis" appropriate for the notions of stochastic convergence and $\beta$-convergence. Furthermore, we performed Granger-causality tests among the catching up variable (the relative LPI with respect to Germany as benchmark country), the Trade Openness and the economic growth proxied by the per capita GDP.

The applied causality tests revealed bidirectional causal relations between GDP and LPI, as well as between GDP and trade (TRP). The PMG approach additionally revealed a univariate causal effect running from TRP to LPI. The lack of evidence in favor of a direct causal effect from logistics performance to trade growth implies that policies aiming to boost logistics performance (e.g., investments in transport infrastructure, promoting ICT adoption in logistics, increasing vehicle load factors) may not directly contribute to international transactions and trade growth. However, there would be some interesting potential to trigger economic growth mechanisms (e.g., through increase in competitiveness by means of lower transportation rates, efficient/consistent deliveries) that would, in turn, stimulate trade growth. Here, it is also important to mention that relevant regulatory reforms or industry action towards improving logistics performance need to be also viewed with consideration to the level of per capita income as suggested by Çelebi (2019). As a matter of fact, low-income economies get more benefit in terms of their export activity from upgrades in logistics performance, while upper-middle and high-income economies tend to increase imports as a result of logistics excellence. Therefore, collaborative action or joint investment plans may need to be brought forward so that the logistics performance of partner countries is upgraded in order to subsequently increase the export activity of upper-middle to high-income countries. Although we did not investigate causal effects in relation to the level of per capita income, there seems to be ample room for future research in this direction.

Regarding the issue of a global tendency to produce logistics services of better quality, we proceeded by applying convergence analysis methodologies using Germany's LPI score as benchmark to detect possible catching up effects from the rest of the countries. The results confirmed the progress of this sector for all the countries in our sample, a fact that is further confirmed by the latest LPI rankings. Furthermore, we performed Granger-causality tests with the aim to investigate whether the global convergence in the quality of the logistics services improves international trade performance and economic growth in a causal way. The findings supported that both international trade and convergence in higher logistics services level constitute driving forces of economic growth. Furthermore, there is evidence that trade and economic growth positively influenced global logistics reducing deviations from Germany that exhibits a dominating role among the countries included in our sample. The latter findings provide sufficient evidence in support of international transport integration and cohesion strategies and investments such as those persistently pursued by the European Commission (e.g., TransEuropean Transport Networks / TEN-T projects, Mobility for Growth Horizon 2020 EU-funded research). Such policies/strategies would contribute in the reduction of extensive differences in logistics infrastructure, service quality and performance after all by promoting convergence with well competent countries in logistics, hence delivering benefits in the form of a more sustainable economic growth. Finally, it is worth mentioning that all indicators comprising the overall LPI index are treated to be of equal importance weight. The impact of a weighted LPI index (Rezaei et al., 2018) on trade openness and economic growth would merit some further research investigation. 


\section{References}

Arvis, J.F., Mustra, M., Panzer, J., Ojala. L. and Naula, T. (2007) Connecting to Compete 2007: Trade Logistics in the Global Economy, Washington, D.C., The World Bank.

Arvis, J.F., Mustra, M., Ojala, J., Shepherd, B. and Saslavsky, D. (2010) Connecting to Compete 2010: Trade Logistics in the Global Economy, Washington, D.C., The World Bank.

Arvis, J.F., Mustra, M., Ojala, J., Shepherd B. and Saslavsky, D. (2012) Connecting to Compete: Trade Logistics in the Global Economy, Washington, D.C., The World Bank.

Arvis, J.F., Saslavsky, D., Ojala, L., Shepherd, B., Busch and C., Raj, A. (2014) Connecting to Compete: Trade Logistics in the Global Economy - The Logistics Performance Index and Its Indicators, Washington, D.C., The World Bank.

Berndt, E.R. and Hansson, B. (1992) Measuring the contribution of public infrastructure capital in Sweden, Scandinavian Journal of Economics, 94, 151-168.

Breitung, J. (2000) The Local Power of Some Unit Root Tests for Panel Data, Advances in Econometrics 15, Nonstationary Panels, Panel Cointegration and Dynamic Panels, Amsterdam: JAI Press, 161-178.

Carlino, G. and Mills, L. (1993) Are U.S. Regional Incomes Converging? A Time Series Analysis, Journal of Monetary Economics, 32, 335-346.

Çelebi, D. (2019) The role of logistics performance in promoting trade, Maritime Economics \& Logistics, 21(3), 307-323.

Choi, I. (2001) Unit root tests for panel data, Journal of International Money Finance, 20(2), 249-272.

Dee, P. and Findlay, C. (2006) Trade Facilitation: What, Why, How, Where and When?, $3^{\text {rd }}$ LAEBA Annual Meeting, Seoul, South Korea.

Ekici, Ş.Ö., Kabak, Ö. and Ülengin, F. (2016) Linking to compete: Logistics and global competitiveness interaction, Transport Policy, 48, 117-128.

Fallahi, F. (2017) Stochastic convergence in per capita energy use in world, Energy Economics, 65, 228-239.

Gani, A. (2017) The Logistics Performance Effect in International Trade, The Asian Journal of Shipping and Logistics, 33(4), 279-288.

Granger, C. W. J. (1969) Investigating Causal Relations by Econometric Models and Crossspectral Methods, Econometrica, 37(3), 424-438.

Hausman, W.H., Lee, H.L and Subramaniam, U. (2013) The impact of logistics performance on trade, Production and Operations Management, 22(2), 236-252.

Hoekman, B. and Nicita, A. (2011) Trade policy, trade costs, and developing country trade, World Development, 39, 2069-2079.

Holmes, M., Otero, J. and Panagiotidis, T. (2014) A Note on the Extent of U.S. Regional Income Convergence, Macroeconomic Dynamics, 18(7), 1635-1655.

Im, K.S., Pesaran, M. and Shin, Y. (2003) Testing for unit roots in heterogeneous panels, Journal of Econometrics, 115(1), 53-74.

Kabak, Ö., Ülengin, F. and Ekici, Ş.Ö. (2018) Connecting logistics performance to export: A scenario-based approach, Research in Transportation Economics, 70, 69-82.

Katrakylidis, I. and Madas, M. (2019) International Trade and Logistics: An Empirical Panel Investigation of the Dynamic Linkages between the Logistics and Trade and their Contribution to Economic Growth, International Journal of Economics and Business Administration, 3(4), 3-21.

Kessides, C. (1996) A review of infrastructure's impact on economic development. In Batten, D., Karlsson, C. (Eds.), Infrastructure and the Complexity of Economic Development, Chapter 12, 213-230.

Kumar Sharma, N. and Singh Kushwaha, G. (2017) A Study on Indian Logistics Network and Its Impact on Economic Growth, IUP Journal of Supply Chain Management, 14(4), 38-60. 
Lee, J.Y. and Rodrigue, J.P. (2006) Trade reorientation and its effects on regional port systems: the Korea-China link along the Yellow Sea Rim, Growth and Change, 37(4), 597-619.

Levin, A., Lin, C.F. and Chu, C.S.J. (2002) Unit root tests in panel data: Asymptotic and finitesample properties, Journal of Econometrics, 108(1), 1-24.

Maddala, G.S. and Wu, S. (1999) A Comparative Study of Unit Root Tests with Panel Data and A New Simple Test, Oxford Bulletin of Economics and Statistics, 61, 631-652.

Nguyen, H.O., and Tongzon, J. (2010) Causal nexus between the transport and logistics sector and trade: The case of Australia, Transport Policy, 17, 135-146.

Portugal-Perez, A. and Wilson, J.S. (2012) Export performance and trade facilitation reform: hard and soft infrastructure, World Development, 40, 1295-1307.

Rietveld, P, (1989) Infrastructure and regional development: A survey of multiregional economic models, The Annals of Regional Science, 23, 255-274.

Rezaei, J., van Roekel, W.S. and Tavasszy, L. (2018) Measuring the relative importance of the logistics performance index indicators using Best Worst Method, Transport Policy, 68, 158169.

Sala-i-Martin, X. (1996) The Classical Approach to Convergence Analysis, The Economic Journal, 106, 1019-1036.

Tomljanovich M, Vogelsang T (2002) Are U.S. regions converging? Using new econometric methods to examine old issues, Empirical Economics, 27, 49-62.

Tsanana, E. and Katrakilidis, C. (2014) Do Balkan economies catch up with EU? New evidence from panel unit root analysis, Empirica, 41, 641-662.

Vasiliauskas, A.V. and Barysiene, J. (2008) An economic evaluation model of the logistics system based on container transportation, Transport, 23(4), 311-315.

Wilson, J., Mann, C. and Otsuki, T. (2003) Trade facilitation and economic development, World Bank Policy Research Working Paper 2988. Washington.

\section{Appendix A - Group of countries}

$\begin{array}{lll}\text { Australia } & \text { Finland } & \text { Netherlands } \\ \text { Austria } & \text { France } & \text { Russian Federation } \\ \text { Argentina } & \text { Germany } & \text { Poland } \\ \text { Belarus } & \text { Greece } & \text { Romania } \\ \text { Belgium } & \text { Hong Kong SAR, China } & \text { Slovak Republic } \\ \text { Brazil } & \text { Hungary } & \text { Serbia } \\ \text { Bulgaria } & \text { India } & \text { Slovenia } \\ \text { Canada } & \text { Ireland } & \text { Spain } \\ \text { China } & \text { Israel } & \text { Sweden } \\ \text { Cyprus } & \text { Italy } & \text { Turkey } \\ \text { Denmark } & \text { Japan } & \text { Ukraine } \\ \text { Czech Republic } & \text { Korea, Rep } & \text { United States } \\ \text { Croatia } & \text { Norway } & \text { United Kingdom }\end{array}$

